\title{
Does N,N-Dimethyltryptamine (DMT) Adequately Explain Near-Death Experiences?
}

\author{
Michael Potts, Ph.D. \\ Methodist University
}

\begin{abstract}
Some NDE researchers have suggested that because some users of psychedelic drugs have experiences purportedly similar to near-death experiences (NDEs), the neural receptors and neurotransmitters affected by a particular drug may underlie out-of-body experiences and NDEs. One of the most recent psychedelic candidates that allegedly causes NDE-like experiences is $\mathrm{N}, \mathrm{N}$-dimethyltryptamine (DMT), a natural substance that the body produces in small amounts. If DMT experiences are phenomenologically similar to NDEs, then it is possible that the human body in extremis may produce larger amounts of DMT that reach psychedelic experience-causing levels in the blood. In this paper, I explore the issue of whether DMT might play a causal role in the production of NDEs. The first section summarizes basic information about NDEs, focusing on their phenomenological aspects. The second section classifies theories of NDEs to place the DMT theory in the context of the history of the debate over the cause of NDEs. The following section discusses DMT's chemical composition, physical effects, and psychological effects. The final section explores whether NDE and DMT experiences have a sufficient degree of phenomenological similarity to justify a causal role for DMT in the production of NDEs and concludes that such similarity is lacking.
\end{abstract}

KEY WORDS: near-death experiences; out-of-body experiences; $\mathrm{N}, \mathrm{N}$ dimethyltryptamine; phenomenology of NDEs

Since the publication of Raymond Moody's Life After Life (1975), authors have produced a plethora of literature on the phenomena he termed "near-death experiences" (NDEs). An NDE is an experience in

Michael Potts, Ph.D., is Professor of Philosophy at Methodist University in Fayetteville, NC. He is grateful for the comments and suggestions of the editor, Janice Miner Holden, and two anonymous referees whose feedback helped him strengthen this article. Correspondence regarding this article should be sent to Dr. Potts at email: mpotts@methodist.edu. 
which a person encounters an actual or anticipated ("fear-death") close brush with death and has the subjective experience of profound peace and/or a sense of one's consciousness functioning apart from the physical body; this latter sense can include a material aspect-perceiving the material world, sometimes termed out-of-body experience (OBE), and/or a transmaterial phase-perceiving and often interacting with environments and entities (deceased loved ones, spiritual/religious figures) not of the material world. Research indicates that approximately one in five people who survive an actual or anticipated close brush with death report an NDE (Zingrone \& Alvarado, 2009). Phenomenologically indistinguishable experiences can occur apart from an actual or anticipated close brush with death, usually in other psychologically extreme states such as profound grief or other emotional arousal, deep relaxation, or intense physical exertion.

As one attempt to explain the origin of NDEs, some researchers have suggested that the activation or inhibition of particular receptor sites in the brain may be the cause of both OBEs and NDEs (Hill \& Persinger, 2003; Jansen, 1989, 1996; Kärkkäinen, Forsström, Tornaeus, Wähälä, Kiuru, Honkanen, Stenman . . Hesso, 2005; Strassman, 1996, 2001; Strassman, Qualls, Uhlenhuth, \& Kellner, 1994). One route these researchers have taken is to suggest that because some psychedelic drugs users' experiences mimic key phenomenological aspects of NDEs, the receptors and neurotransmitters that the drug affects may underlie and, therefore, be responsible for producing, OBEs and NDEs. The drugs they have implicated include LSD, psilocybin, and ketamine. One psychedelic candidate that allegedly causes NDE-like experiences is N,N-dimethyltryptamine (DMT), a natural substance produced by the body in small amounts (Strassman, 2001). If DMT experiences are phenomenologically similar to NDEs, then it is possible that the human body in extremis may produce larger amounts of DMT that reach psychedelic-causing levels in the blood.

In this article, I explore the issue of whether DMT plays a causal role in the production of NDEs. The first section will summarize basic information about NDEs, with a focus on their phenomenological aspects. The second section will classify theories of NDEs to place the DMT theory in the context of the history of the debate over the cause of NDEs. The following section will discuss DMT's chemical composition, physical effects, and psychological effects. The final section will explore whether NDE and DMT experiences have a sufficient degree of phenomenological similarity to substantiate a causal role for DMT in the production of NDEs. 


\section{Near-Death Experiences (NDEs)}

Rense Lange, Bruce Greyson, and James Houran (2004) defined NDEs as "transcendental experiences precipitated by a confrontation with death and which do not seem to be accounted for by our current understanding of the dying process" (p. 161). Michael Sabom (1982) has proposed a useful distinction between "autoscopic" and "transcendental" NDEs. The autoscopic NDE involves a sense of separation from the body and may include seeing one's physical body as well as seeing and hearing one's resuscitation. The transcendental NDE involves visions of "another world," including experiences of religious figures, such as angels or God. Janice Miner Holden (2009) made a similar distinction, referring to the "material aspect" and "transmaterial aspect" (p. 185) of NDEs. Both involve the experience of one's consciousness functioning apart from the physical body. The material aspect involves an NDEr perceiving-seeing, hearing, etc.-material phenomena, mainly but not exclusively in the area surrounding her body. These phenomena include the NDEr's body itself and/or the people, objects, and environments surrounding or distant from the body. The transmaterial aspect involves perceiving "phenomena in transcendent dimensions beyond the material world" (p. 185)-environments often of exceptional beauty and entities such as deceased loved ones and spiritual/religious figures.

The "gold standard" in assessing whether a person has experienced an NDE and the depth of the experience is the Near-Death Experience Scale (Greyson, 1983). Greyson (1983) culled the Scale's 16 questions from a list of 80 features associated with NDEs. Among other experiences, the questions address temporal distortions, feelings of peace, a sense of separation from the body, and encountering dead relatives (Lange et al., 2004). For each question, the respondent subjectively rates the feature on a three-point scale: 0 indicating no experience of that feature, 1 indicating a mild experience, and 2 indicating the most intense experience. The Scale has been useful in distinguishing NDEs from other kinds of experiences. For a person to be considered as having an NDE, she must score seven or above, with higher scores indicating more features or more subjectively intense features.

The phenomena listed do not necessarily all take place in an NDE, and when they do, they do not occur in a set order. Most NDEs do not go beyond the feeling of peace or joy. However, full-fledged experiences that contain both material-world perceptions and transcendental elements can be impressive, especially if a patient details seeing her own 
body and what was being done to it during, for example, open-heart surgery (see Sabom, 1982; Holden, 2009). Such cases of veridical NDE perception raise the issue of whether some spiritual part of a person really does separate from the body during NDEs. If so, NDEs could be construed as evidence of at least a temporary survival of a conscious part of a person after clinical death (cardio-pulmonary arrest). This possibility would still not answer the question of whether survival continues after the point of no return to physical existence that marks irreversible biological death. However, if a conscious part of people survives clinical death, the probability increases of survival beyond biological death.

\section{The DMT Theory in the Spectrum of Theories of the Causes of NDEs}

Theories of NDEs are divided into three main classes: (1) psychological theories, (2) physiological theories, and (3) non-materialistic ("spiritual" or "transcendental" theories; Greyson, Kelly, and Kelly, 2009). Psychological and physiological theories tend to be reductionist and deny that NDEs are anything more than the result of a particular psychological or physiological mechanism. However, such theories need not be reductionist; for example, if NDEs were correlated with low blood oxygen levels (current evidence is ambiguous; in a study of NDEs in cardiac arrest patients, those people having a near-death experience had higher blood oxygen levels than the non-experiencers; Parnia, Waller, Yeates, and Fenwick, 2001—but Michael D. Gliksman and Allan Kellehear (1990) argue that blood gas levels in cardiac arrest patients are not reliable indicators of actual cerebral oxygen levels), it is still possible that NDEs could reveal some kind of extraordinary perception or transcendent realm. The physiological theorist would have to further argue from parsimony to make her case.

Psychological theories can be divided into the following categories:

1. Fantasy or depersonalization to protect a person from the fear of death (Noyes \& Kletti, 1976, 1977; Siegel, 1980)

2. A reliving of the birth experience (Sagan, 1979)

3. The role of personality factors in generating NDEs:

A. Fantasy-proneness (Wilson \& Barber, 1983)

B. Absorption (Tellegen \& Atkinson, 1974)

C. Dissociative tendencies (Irwin, 1993) 
The weakest of the psychological theories is Carl Sagan's view that an NDE involves memories of the experience of birth, because the newborn baby's brain is not developed enough to have sufficient cognitive capacity to remember the birth experience (Becker, 1982). In Becker's critique of Sagan's hypothesis, he also noted the fatal flaw in reductionist psychological theories: that they commit the genetic fallacy. The ultimate nature of NDEs cannot be decided in terms of psychological correlations with NDEs; NDEs could be ontologically transcendental experiences and a way to find peace at death. Psychology is not metaphysics. The genetic fallacy is particularly seen in Ronald K. Siegel's (1980) article in which he went into detail on a history of human psychological motivations for belief in life after death, including explaining phenomena surrounding death such as dreaming of the deceased and phenomena such as rebirth in nature in springtime. In a sharp exchange, Ian Stevenson (1981) noted that the origin of human belief in life after death is irrelevant its truth or falsity. However, Siegel (1981) went on to argue that such psychological continuities have behind them common biological reactions to stimuli, common brain structures, and common patterns resulting from environmental stimuli that are exemplified by NDE and other phenomena surrounding death.

Reductionists have also tried to explain NDEs by physiological and pharmacological means. This is a broader category of potential explanations and includes:

1. Temporal lobe excitation (Britton \& Bootzin, 2010; Neppe, 1983, 1989; Persinger, 1989; Saavedra-Aguilar \& Gómez-Jeria, 1989;)

2. Anesthesia (awareness during anesthesia to explain continued sense awareness of surgical patients who have NDEs; Blackmore, 1993)

3. Hypercapnia (also called "hypercarbia"), an excess of carbon dioxide in the blood (Blackmore, 1993; Klemenc-Ketis, Kersnik, \& Grmec, 2010)

4. Hypoxia (a low blood oxygen level; Blackmore, 1993)

5. Natural endorphins and neurotransmitters (whose reception sites may be affected by psychedelic drugs such as LSD, ketamine, and DMT (see Morse, Venecia, \& Milstein, 1989).

Greyson (2000, 2010), along with his colleagues (Kelly, Greyson, \& Kelly 2007), have summarized objections to physiological reductionism, employing two major prongs: (1) patients while having NDEs are not in the physiological state demanded by a particular physiological theory, and (2) the phenomenology of NDEs differs in significant 
ways from experiences resulting from physiological causes that allegedly cause NDEs. Experiences of persons suffering from hypercapnia/ hypercarbia or hypoxia are often more emotionally distressing than the majority of NDEs are, and they are often disjointed, more like a dream than like the sense of reality that characterizes most NDEs. NDErs uniformly claim what William James (1997/1902) called (referring to mystical experiences) a "noetic quality" to their experiences: The experiences felt "realer than real." Temporal lobe epilepsy and temporal lobe lesions result in less unified experiences than characterize NDEs, and most people who have such experiences believe them to be imaginary, in contrast to most NDErs' view that their NDEs actually happened.

Contemporary physiological theories follow that of Susan Blackmore (1993) in developing a multi-causal model for NDEs. For example, DMT release might explain some NDEs or parts of NDEs, and hypoxia or hypercapnia might explain others. Temporal lobe excitation may be involved. This approach may be vulnerable to the objection that multiple leaky buckets still leak; that is, multiple weak physiological theories do not explain NDEs any better than one weak physiological theory. In addition, as Emily Kelly and her colleagues (Kelly et al., 2007) pointed out, major elements of NDEs, including their noetic quality, the life review, and meeting deceased relatives are not accounted for in many physiological theories. No physiological theory, they suggest, can explain veridical perception of loved ones who have died when the NDEr does not know prior to the NDE that the person has died. Thus, even combinations of physiological theories fail to adequately explain NDEs.

The weaknesses in other physiological theories will be shown to haunt the position that NDEs are caused by naturally psychotropic hormones in the body released near actual or feared death. It is also alleged that psychedelic drugs that act on those receptors result in a subjective state that mimics key features of NDEs. One candidate often discussed is ketamine, an animal anesthetic that in the past was used on humans, that affects NMDA receptors, and that results in psychedelic affects in humans (Jansen, 1989, 1996). Although Karl Jansen's claims have been sharply criticized (Bianchi, 1997; Fenwick, 1997; Kungurtsev, 1997; Morse, 1997; Twemlow \& Gabbard, 1997; see also Jansen, 1997, in which he replied to his critics), I will use ketamine as an example of how drugs can be used to make a reductionist argument regarding NDEs: 
1. Ketamine results in subjects experiencing phenomenological features found in NDEs, often surpassing a score of seven on the NDE Scale.

2. Ketamine acts on neurotransmitter receptor site $\mathrm{S}$ that is sensitive for neurotransmitter Y.

3. It is probable that Ketamine mimics the effects of large doses of Y.

4. Thus higher than normal levels of $Y$ in extremis can trigger NDEs.

5. From an evolutionary perspective such high levels may function to calm an organism that is facing death.

As previously stated, not everyone who believes that neurotransmitters play a key role in causing NDEs are reductionists. For example, Rick Strassman, who has performed extensive experiments with DMT, is not a reductionist; see his discussion of ketamine in Strassman (1997). It may be the case that certain events must happen in the brain to "trigger" the soul's release from the body, and these events will involve neurotransmitters. However, a skeptic concerning the existence of the soul, a transcendent realm, and/or survival of death could argue that if neurotransmitter release can explain the formation of NDEs, there is no need to posit a soul or support any survivalist interpretation of NDEs. Although I have argued elsewhere (Potts, 2011) that Occam's Razor is not decisive in rejecting a particular scientific explanation, an analysis of the subjective states resulting from a particular psychedelic and those of NDEs could at least answer the question of whether NDEs are sufficiently similar to a drug-induced experience to suggest that they involve the same chemical facilitator.

The debate over this issue has been extensive, beginning with the discussion regarding whether drug-induced experience could induce a mystical or transcendental experience in general. William James (1997/1902) suggested a non-reductionist interpretation of his experiences with nitrous oxide. Later, Aldous Huxley (1954), Huston Smith (2000), and Stanislav Grof (2009) all suggested that psychedelic drugs such as mescaline (Huxley) and LSD (Smith, Grof) could open the door to a transcendent realm, with R. C. Zaehner (1957) strongly disagreeing. With the beginning of the modern study of NDEs, this debate extended to those experiences. The debate has ranged over the major psychedelics, although focusing mainly on LSD, ketamine, and DMT (Greyson, 2000, 2010; Greyson, Kelly, \& Kelly, 2009; Grof, 1985, 2009; Jansen, 1989, 1996; Luke, 2008; Morse et al., 1989; Ring, 1988; Rogo, 1984; Siegel, 1980; Strassman, 1996, 2001; Strassman et al., 1994; Yensen, 1988). The main issue is whether there is any more to NDEs than a physical experience caused by a neurological reaction to 
psychedelic-like substances in the body. A secondary issue is whether psychedelics themselves are doorways to a transcendent realm. With this debate in mind, the next section will address DMT.

\section{DMT}

DMT and its close relative 5-methoxy-N,N-dimethyltryptamine (5-MeO-DMT, also known as bufotenine due to its presence in the venom of frogs from the Bufo genus) were first used as psychedelic substances by the native tribes of South America, especially in the Amazon region of Brazil (Stafford \& Bigwood, 1993). They were used in religious ceremonies, medicine, magic, and various rites of passage and are still used today by two Brazilian religious groups: the Santo Daime and the Uniao de Vegetal (Riba, Valle, Urbano, Yritia, Morte, $\&$ Barbancu, 2003). The natives and the religious groups drink a beverage called ayahuasca that combines various parts of native plants. The active ingredients are DMT and monoamine oxidase inhibitors.

Since the synthesis of DMT in 1931, it has been researched, especially from the 1950s (Szara, 2007) until it was placed on Schedule I of the Controlled Substances Act in 1970, although there was already a trend toward making it illegal in individual state laws (Stafford \& Bigwood, 1993). Since then, research has been more sporadic on DMT-and on psychedelics in general-but recent speculation about a possible causal role of DMT in schizophrenia has kept interest alive in DMT research (see, for example, Heller, Narasimhachari, Spaide, Haskovec, \& Himwich, 1970; however, more recent research has yielded conflicting results; see Gable, 2007), and the pace of research articles published on DMT has increased.

In these publications, researchers have reported on their investigations of DMT's chemical properties, pharmacology, and psychedelic effects. DMT is synthesized from the amino acid tryptophan (Jacob \& Presti, 2004). Its molecular structure is simpler than the other tryptamine psychedelics such as psilocybin and bufotenine (Gable, 2007; Strassman, 2001). Solomon Snyder and Elliot Richelson (1968) found that tryptamines and other classes of psychedelics "all approximate a unique conformation, simulating in part rings A, B, and C of LSD" (p. 206). DMT is chemically similar to serotonin, and like LSD and psilocybin, DMT is a serotonin agonist at the 5-hydroxytryptamine $\left(5-\mathrm{HT}_{2 \mathrm{~A}}\right)$ and $5-\mathrm{HT}_{2 \mathrm{C}}$ receptors (Riba, Valle, Urbano, Yritia, Morte, \& Barbanoj, 2003; Yritia, Riba, Ortuño, Ramirez, Castillo, Alfaro . . . Barbanoj, 2002). This similarity is important because 
5-HT receptor sites exist in human central tissue in areas known to subserve emotional, perceptual, and somatosensory function. . . . 5HT2 receptors were found in human cortical areas, mammillary bodies, claustrum, amygdala, caudate, putamen, nucleus accumbens, hippocampus. . . cortex and striatum" (Strassman et al., 1994, p. 103).

The function of endogenous DMT is unknown. Endogenous DMT has been found in smaller amounts in urine and blood and in larger amounts in the stool, which has led to the suggestion that DMT may play some role in intestinal function (Kärkkäinen et al., 2005). However, Michael Jacob and David Presti (2005) pointed to recent research revealing the role of neurotransmitters outside the brain, including those in the gut, in helping to establish mood. They suggested that natural DMT has a calming rather than a psychedelic effect, which they believe has to do with DMT's affinity for the trace amine (TA) receptor. Strassman (2001) suggested that the pineal gland may produce DMT, referring to its secretion of the non-psychedelic tryptamine $\mathrm{N}$-acetyl-5-methoxytryptamine (melatonin).

Natural DMT is quickly broken down in the body, most likely through "first-pass enzymic degradation by monoamine oxidase (MAO)" (Yritia et al., 2002, p. 272). Without a monoamine oxidase inhibitor such as harmaline, which is found along with DMT and other MAOIs in the ayahuasca beverage, orally ingested DMT is dormant (Yritia et al., 2002). Besides oral ingestion, DMT can be smoked, snorted, or injected (Rodriguez, 2006). Early on, Stephen Szara (1969) discovered that DMT's effect on animals is similar to the effects of mescaline and of LSD, although with short-lasting action: 45 minutes to one hour. Animals given 5-MeO-DMT engage in "head shaking, forepaw treading, flat-body posture, straub tail, and hindlimb abduction" (Shen, Jiang, Winter, \& Yu, 2010, p. 661), behaviors that are standard responses to many hallucinogens; the authors noted that it also leads to sham rage in cats. Szara (1956) also discovered the psychedelic properties of DMT in humans: "visual hallucinations and illusions, distorsion [sic] of the spatial perception and body image, disturbances of thought and speech, euphoria" (Szara, 1956, p. 441). Physical symptoms include an increase in heart rate and blood pressure and pupillary dilation (Strassman, 2001; Szara, 1956).

Strassman and his colleagues (Strassman et al., 1994) have done the most recent detailed studies of DMT's effects on humans. With 12 subjects who were experienced users of psychedelics, they administered DMT via IV; one subject dropped out of the experiment. At first, on different days subjects would receive a low dose $(0.04 \mathrm{mg} / \mathrm{kg})$ and 
a high dose $(0.4 \mathrm{mg} / \mathrm{kg})$ of DMT. Later, in a double-blind study with saline placebo, they received doses of $0.05,0.1,0.2$, and $0.4 \mathrm{mg} / \mathrm{kg}$. Doses of 0.2 and $0.4 \mathrm{mg} / \mathrm{kg}$ resulted in "the nearly instantaneous onset of visual hallucinatory phenomena, bodily dissociation, and extreme shifts in mood. . . . Auditory effects were noted in about half the subjects" (Strassman et al., 1994, p. 101). At the highest dose, subjects experienced a nearly immediate "rush" in which the normal perceptual field was replaced with a hallucinogenic one. The psychological effects peaked after two minutes and ended in most subjects by 30 minutes (Strassman, 1996). Subjective experiences that Strassman and his colleagues (1994) reported were almost all visual and included "concrete, well-formed, visual images" such as "a fantastic bird" or "human and 'alien' figures" (p. 100). Subjects also reported less specific visual images such as unusually intense colors or "beautiful, colorful pink cobwebs" (p. 100). Auditory effects including "chattering" or "enhanced 'auditory acuity" (p.101). Cognitive effects ranged from "ineffability" to a "sense of experiencing "full intelligence' or 'full consciousness' - but an 'emotionally detached' entity" (p. 102). Some subjects also reported a sense of "an almost complete loss of control" (p. 102).

In another study, researchers compared the psychological effects of DMT and ketamine in nine (of an original fifteen) healthy subjects who completed the experiment by being given both drugs (GouzoulisMayfrank, Heekeren, Neukirch, Stoll, Stock, Obradovic, \& Dovar, 2005). Some types of experiences were common to both drugs, such as bodily misperceptions, including a sense of the body melting and a sense that even soft contact on the body made permanent indentations. Subjects experienced their body boundaries as vague. Also, high doses of both drugs resulted in paranoia and a sense of "altered meaning or significance" (p. 307). Visual hallucinations were more common with DMT, and subjects given DMT also reported auditory sensations of hearing whispering or a telephone ringing. Visual hallucinations associated with DMT administration included "complex geometrical patterns on the walls and body parts on the computer screen" (p. 307). Two subjects during DMT administration showed evidence of paranoia, believing that the scientists conducting the experiment were being directed by a higher being of some kind. Subjects' thinking became disorganized, and logical connections between propositions loosened. Mood changes occurred, but two subjects felt anxious because they did not believe the mood changes were real as much as caused by DMT.

Ketamine led to "dose-dependent hypomimia, psychomotor poverty, 
poverty of speech, apathy and withdrawal. Six subjects displayed catatonic-like behavior" (Gouzoulis-Mayfrank et al., 2005, pp. 207208), and all subjects displayed emotional blunting and detachment from other people. Visual hallucinations occurred in only one subject, which involved "cartoon-like figures moving on the computer screen" (p. 208). Some subjects reported a sense of the body moving through space. With only one exception, subjects found the experience unpleasant. The authors concluded that DMT, an LSD-like drug, causes symptoms similar to the positive effects of schizophrenia, and ketamine, which is similar to PCP, causes symptoms similar to the negative effects.

Strassman (2001) was impressed with the subjects in his experiments who had visions of races of beings that the patients interpreted as "transdimensional" or "extraterrestrial." Subjects reported hallucinations of intelligent insectoid and reptilian beings, and some hallucinations involved aliens experimenting and probing the subjects. A few subjects experienced NDE-like visions, including a vision of a tunnel that included seeing gremlin-like antagonistic beings as well as good beings who were aiding the subject. Strassman (2001), like Rodriguez (2006) after him, went as far as to suggest that the "realms" the subjects experienced might actually exist on some world in another dimension. But, in my view, this interpretation lends too much evidential value to the subjective certainly of some subjects that their experience was of an alternate dimension or world. Subjective certainty does not imply the truth of that about which one is certain. Person P could be certain that she sees a rabbit 20 yards from heruntil she draws closer and sees that the animal is a squirrel. Her certainty that she saw a rabbit does not turn a squirrel into a rabbit. Such a "noetic quality," a sense of certainty that one is gaining knowledge through an experience, is also present in mystical experiences, as William James (1902/1997) noted. As James recognized, although such knowledge may have overwhelming epistemic value for the person who had the experience, it does not necessarily have such epistemic value for those who did not have it.

\section{Does DMT Underlie NDEs?}

D. R. Hill and Michael Persinger (2003) argued that mystical experiences of all types, in which category they included NDEs, might be caused by strong magnetic fields that trigger the release of DMT by the pineal gland. They conducted an experiment in which weak elec- 
tromagnetic fields were released into both cerebral hemispheres; the most vivid experiences occurred when the magnetic fields sent to the right hemisphere were $10 \%$ more intense than those sent to the left. Subjects experienced a sense of separation from their bodies, a white light, a sense of bodily deformation, and entities such as deceased relatives or another kind of being. They also experienced hallucinations of "cartoon characters, specific animals, insects, and reptilianlike references" (p. 1049). In addition, some experienced "odd tastes and smells and intense fear" (p. 1049). Hill and Persinger (2003) hypothesized that higher DMT levels will correlate with magnetic field signals sent to the brain. A major problem with Persinger's studies, however, was noted by Pehr Granqvist and his associates (Granqvist, Fredrikson, Unge, Hagenfeldt, Valind, Larhammar, \& Larsson, 2005) who used Persinger's equipment and found that suggestion from the experimenter, rather than weak magnetic fields, was the cause of the reported sensory experiences. This result led to considerable discussion and controversy, and debate has continued (Larsson, Larhammer, Fredrikson, \& Granqvist, 2005; Persinger \& Koren, 2005; St.-Pierre \& Persinger, 2006).

Van Lommel (2010) expressed the belief that DMT production is stimulated by epinephrine and norepinephrine. He indicated that two factors may increase the amount of DMT near death: (1) release of epinephrine and norepinephrine in response to the stress of terminal illness or injury, and/or (2) massive release of DMT by the pineal gland as the body begins the dying process. Van Lommel claimed that experiences similar to NDEs occur with the use of DMT. But I find problems with his position, specifically the absence of evidence for either mechanism and especially that either mechanism produces DMT in large enough amounts for psychedelic effects. These questions could be investigated. Researchers could measure the amount of DMT in the blood and/or tissues at the time of cardiac arrest and afterward to know that there is a correlation between cardiac arrest and sufficiently high levels of DMT. However, even if correlations could be shown, it would not count as causation without particularly strong evidence. I believe the value of van Lommel's theories is to provide models for designing future experiments to test them.

Strassman (2001) and Hill and Persinger (2003) have independently made a strong claim: that DMT plays the main causal role in producing all mystical experience and all NDEs. Even van Lommel has not gone that far. But as Peter Fenwick (1997), speaking of ketamine, has noted, a particular drug such as ketamine may be involved 
in some, but not necessarily all, NDEs. The same could be speculated regarding DMT. This assumption seems reasonable given the variety of situations in which NDEs occur. Although the claim that one drug, endogenous DMT, may produce NDEs while the body is near death and under great stress, is a simple hypothesis, it ignores the multiple redundancies and different sets of neurons (and sometimes different neurotransmitters) that yield similar experiences and behaviors. It is also possible that multiple systems contribute to NDEs; perhaps a ketamine-like blockage of the N-methyl-D-aspartate (NMDA) receptor combined with DMT's action are necessary and jointly sufficient conditions for an NDE to occur. Fenwick (1997) also noted that because NDEs occur in many different situations, not all involving a shock to the brain through lack of oxygen or some other issue, it is unlikely that a single neuroprocess is the cause of all or most NDEs.

In addition, one should consider evidence of veridical perceptions occurring that go beyond current explanatory models of brain functioning. Pam Reynolds (Holden, 2009; Sabom, 1998) is a case in point. In order to have a large basilar artery aneurysm safely removed from her brain, there was a need to drain her blood, cool her body, and stop her heart. Near the start of the surgery, before cardiac arrest took place, she was fully anesthetized with eyes taped shut and ears plugged with speakers. Loud, rapid clicks were transmitted to one ear and white noise in the other. Her head was covered except for area around the incision. Yet despite the sensory blockage due both to being anesthetized and to the lack of visual and auditory input by normal means, Reynolds gave a detailed accounting of her surgery afterwards, with a number of specific facts verified, including the use of a bone saw and a groin incision. She heard a female voice saying that her right side vessels were too small and a male voice saying to try making an incision in the other side (Holden, 2009; Sabom, 1998). She also had a transcendental NDE in which she saw deceased relatives, possibly during the time she was in cardiac arrest, though it is impossible to tell for sure. However, it remains an impressive case.

Many NDEs occur after cardiac arrest, a devastating insult to the body that leads to a flat EEG in less than a minute. While the EEG only measures neocortical activity, a lack of cortical activity is at least prima facie evidence for a lack of consciousness-yet NDErs often have experiences in which they present specific, verifiable details about their resuscitations, have transcendental experiences that have a strong narrative structure (instead of the often choppy experiences involving DMT or ketamine), and occur with a clear sensorium 
(Greyson, 2000, 2010; Greyson, Kelly, and Kelly, 2009). The increasing number of veridical NDEs documented, including some in children, suggests that something other than an endogenous drug-based theory is adequate (see Ring \& Lawrence, 1993; Rousseau, 2012).

Importantly, adherence to a DMT or ketamine model does not negate the possibility that NDEs are evidence of survival of death, of a soul that is separable from the body, or of some kind of "universal consciousness." Van Lommel (2010) is a case in point, with his belief that the pineal gland, through its release of DMT, is the body's link to universal, nonlocal consciousness. Strassman (2001) believed in the ontological reality of the claims of beings from other dimensions DMT experiencers claim to see. Rodriguez (2006) agreed. Such an emphasis on the pineal gland as the link between worlds sounds a great deal like René Descartes's (1649/1989) claim that the pineal gland is the central point at which the soul interacts with the body (Lokhorst, 2008).

The most compelling reason against the DMT hypothesis of NDEs is the same reason the ketamine theory is flawed: The phenomenology of drug-facilitated experiences is far more different from than it is similar to the phenomenology of NDEs. An examination of the DMT literature indicates that studies such as Christopher Cott and Adam Rock's (2008) and David Luke's (2011) that argued for a similarity between DMT phenomenology and NDEs - with the former report emphasizing noetic quality and ineffability and the latter the appearance of discarnate entities-do not square with the bulk of the evidence. This is a similar problem to the one ketamine faces: The predominantly emotionally distressing experiences of ketamine do not square with the predominantly emotionally pleasurable NDEs. In the case of DMT, Strassman's list of experiences can be compared to the items of the NDE Scale that reflect common-phenomenology from among hundreds of NDEs. The NDE Scale includes questions about the following (modified from Greyson, 2007, p. 409); components similar to those in DMT phenomenology are italicized:

\section{Cognitive items}

Time distortion

Thought acceleration

Life review

Sudden understanding

Affective items

Peace

Joy 
Feeling of cosmic unity

Light

Purportedly paranormal experiences

Sensory vividness

Extrasensory perception

Precognitive visions

Out-of-body experience

Transcendental items

Unfamiliar environment

Unidentified "presence"

Religious or deceased spirits

Border or "point of no return"

The list of DMT experiences gleaned from Strassman (2001) includes the following; components similar to those in NDE phenomenology are italicized:

Vivid colors

A Taj Mahal-like building

A merry-go-round with people in 1890s outfits

Clowns (very common)

Circus imagery (very common)

Emotional shock

A sense of annihilation of personal identity

Feeling loved

Gaining information

Noetic quality ("realer than real")

DNA-like spirals

Alphabet-like shapes

Reptilian or insectoid alien beings

High-tech machine-like objects

Computer Board

Ballroom

Being on an operating table with "entities" examining the experiencer

"Angelic singing" by "impersonal beings"

Bright light

Sense of separation from the body

Programmed stick figures as in a video game

Crocodiles raping and crushing an experiencer

A great, impersonal power behind all things

Hundreds of forms of beautiful women

Although some similar phenomena are common to both experiences, many unique phenomena characterize each of them. All perception involves interpretation, but it would be difficult in this case to 
attribute content differences to interpretation alone. In addition, some similarities do not parallel these two experiences alone; ineffability, for example, characterizes mystical or religious experiences in general. On the other hand, the particular ineffability of the two experiences is only superficially similar: The ineffability of being probed by aliens is not similar to the ineffability of NDEs. Both the less common distressing NDEs (Bush, 2009) and DMT experiences involve demonic beings, but NDEs lack the science-fiction setting that often characterizes DMT experiences. Furthermore, some aspects of DMT experience resemble other psychedelic experiences more than NDEs; for example, the sense of alienation from one's body is similar in DMT and in the other psychedelic experiences psychedelics of ketamine and LSD. And importantly, frequent or key NDE phenomena have not, to my knowledge, been reported among DMT experiencers, such as traveling through a tunnel into a transcendent realm or reporting subsequent to the experience that one perceived veridically during it. And finally, aftereffects of the experiences are dissimilar: Apparently permanent changes after NDEs are the rule rather than the exception (Noyes, Fenwick, Holden, \& Christian, 2009) but after DMT experiences are the exception rather than the rule (Strassman, 2001).

This argument is not to claim that DMT plays no contributing role at all in the production of NDEs: It very well may. But thus far the evidence in its favor is not as strong as its advocates, such as Strassman and van Lommel, have claimed. If NDEs are neurally mediated, it is more likely that such complex experiences involve multiple neurotransmitters and regions of the brain other than or in addition to HT serotonin receptors. Veridical perceptions and complex experiences of NDErs during total anesthesia and cardiac arrest support the possibility that nonphysical mechanisms may be at work in NDEs, or if the mechanisms are physical, they appear to defy the prevailing conception of science. At this stage the cause or causes of NDEs cannot be identified with reasonable certainty. Rather, there is, given the evidence, reasonable certainty that DMT is neither the only nor the chief mechanism in the production of NDEs.

\section{References}

Becker, C. B. (1982). The failure of saganomics: Why birth models cannot explain near-death phenomena. Anabiosis: The Journal for Near-Death Studies, 2, 102-109.

Bianchi, A. (1997). Comments on "The ketamine model of the near-death expe- 
rience: A central role for the n-methyl-d-aspartate receptor." Journal of NearDeath Studies, 16, 71-78.

Blackmore, S. (1993). Dying to live: The science of near-death experiences. Buffalo, NY: Prometheus Books.

Britton, W. B. \& Bootzin, R. R. (2004). Near-death experiences and the temporal lobe. Psychological Science, 15, 254-258.

Bush, N. E. (2009). Distressing Western near-death experiences: Finding a way through the abyss. In J. M. Holden, B. Greyson, \& D. James (Eds.), The handbook of near-death experiences: Thirty years of investigation (pp. 63-86). Santa Barbara, CA: Praeger/ABC-CLIO.

Cott, C., \& Rock, A. Phenomenology of N,N-dimethyltryptamine use: A thematic analysis. Journal of Scientific Exploration 22, 359-370.

Descartes, R. (1989). The passions of the soul (H. S. Voss, Trans.). Indianapolis, IN: Hackett. (Original work published 1649)

Fenwick, P. (1997). Is the near-death experience only n-methyl-d-aspartate blocking? Journal of Near-Death Studies, 16, 43-53.

Gable, R. S. (2007). Risk assessment of ritual use of oral dimethyltryptamine (DMT) and harmala alkaloids. Addiction, 102, 24-34.

Gliksman, M. D. \& Kellehear, A. (1990). Near-death experiences and the measurement of blood gases. Journal of Near-Death Studies, 9, 41-43.

Gouzoulis-Mayfrank, E., Heekeren, K., Neukirch, A., Stoll, M., Stock, C., Obradovic, M., \& Dovar, K.-A. (2005). Psychological effects of (s)-ketamine and N,N-dimethyltryptamine (DMT): A double-blind, cross-over study in healthy volunteers. Pharmapsychiatry, 38, 301-311.

Granqvist, P., Fredrikson, M., Unge, P., Hagenfeldt, A., Valind, S., Larhammar, D., \& Larsson, M. (2005). Sensed presence and mystical experiences are predicted by suggestability, not by the application of transcranial weak complex magnetic fields. Neuroscience Letters, 379, 1-6.

Greyson, B. (1983). The Near-Death Experience Scale: Construction, reliability, and validity. Journal of Nervous \& Mental Disease, 171, 369-375.

Greyson, B. (2000). Near-death experiences. In E. Cardeña, S. J. Lynn, \& S. Krippner (Eds.), Varieties of anomalous experience: Examining the scientific evidence. Washington, DC: American Psychological Association.

Greyson, B. (2007). Consistency of near-death experience accounts over two decades: Are reports embellished over time? Resuscitation, 73, 407-411.

Greyson, B. (2010). Implications of near-death experiences for a post-materialist psychology. Psychology of Religion and Spirituality, 2, 37-45.

Greyson, B., Kelly, E. W., \& Kelly, E. F. (2009). Explanatory models for neardeath experiences. In J. M. Holden, B. Greyson, \& D. James (Eds.), The handbook of near-death experiences: Thirty years of investigation (pp. 213-234). Santa Barbara, CA: Praeger/ABC-CLIO.

Grof, S. (1985). Beyond the brain: Birth, death and transcendence in psychotherapy. Albany, NY: State University of New York Press.

Grof, S. (2009). LSD: Doorway to the numinous:Tthe groundbreaking psychedelic research into realms of the human unconscious. Rochester, VT: Park Street Press.

Heller, B., Narasimhachari, N., Spaide, J., Haskovec, L., \& Himwich, H. E. (1970). N-dimethylated indolamines in blood of acute schizophrenics. Experimentia, 15, 503-504. 
Hill, D. R., \& Persinger, M. A. (2003). Application of transcerebral, weak (1 microT) complex magnetic fields and mystical experiences: Are they generated by field-induced dimethyltryptamine release from the pineal organ? Perceptual and Motor Skills, 97, 1049-1050.

Holden, J. M. (2009). Veridical perception in near-death experiences. In J. M. Holden, B. Greyson, \& D. James (Eds.), The handbook of near-death experiences: Thirty years of investigation (pp. 185-212). Santa Barbara, CA: Praeger/ ABC-CLIO.

Huxley, A. (1954). The doors of perception. New York, NY: Harper \& Row.

Irwin, H. J. (1993). The near-death experience as a dissociative phenomenon: An empirical assessment. Journal of Near Death Studies, 12, 95-103.

Jacob, M. S., \& Presti, D. E. (2005). Endogenous psychoactive tryptamines reconsidered: An anxiolytic role for dimethyltryptamine. Medical Hypotheses, 64, 930-937.

James, W. (1997). The varieties of religious experience. New York, NY: Touchstone, 1997. (Original work published 1902)

Jansen, K. (1989). Near death experience and the NMDA receptor (Letter). British Medical Journal, 298, 1708.

Jansen, K. (1996). Neuroscience, ketamine, and the near-death experience: The role of glutamate and the NMDA receptor. In L. W. Bailey \& J. Yates (Eds.), The near-death experience: A reader (pp. 265-282). New York, NY: Routledge.

Jansen, K. (1997). Response to commentaries on "The ketamine model of the near-death experience. .." Journal of Near-Death Studies, 16, 79-95.

Kärkkäinen, J., Forsström, T., Tornaeus, J., Wähälä, K., Kiuru, P., Honkanen, A., Stenman, U.-H., Turpeinen, U., \& Hesso, A. (2005). Potentially hallucinogenic 5 -hdroxytryptamine Receptor ligands bufotenine and dimethyltryptamine in blood and tissues. Scandinavian Journal of Clinical and Laboratory Investigation, 65, 189-199.

Kelly, E. W., Greyson, B., \& Kelly, E. F. (2007). Unusual experiences near death and related phenomena. In E. F. Kelly, E. W. Kelly, A. Crabrtee, A. Gauld, M. Grosso, \& B. Greyson, B., Irreducible mind: A psychology for the 21st century (pp. 367-421). Lanham, MD: Rowman and Littlefield.

Klemenc-Ketis, Z., Kersnik, J., \& Grmec, S. (2010). The effect of carbon dioxide on near-death experiences in out-of-hospital cardiac arrest survivors: A prospective observational study. Critical Care, 14, R56. doi:10.1186/

Kungurtsev, I. (1997). Which comes first: Consciousness or aspartate receptors? Journal of Near-Death Studies, 16, 55-57.

Lange, R., Greyson, B., \& Houran, J. (2004). A Rasch scaling evaluation of a 'core' near-death experience. British Journal of Psychology, 95, 161-177.

Larsson, M., Larhammar, D., Fredrikson, M., \& Granqvist, P. (2005). Reply to M. A. Persinger and S. A. Koren's response to Granqvist et al., "Sensed presence and mystical experiences are predicted by suggestibility, not by the application of transcranial weak magnetic fields." Neuroscience Letters, 380, 348-350.

Lokhorst, G.-J. (2008). Descartes and the pineal gland. In E. N. Zalta (Ed.), Stanford encyclopedia of philosophy. Stanford, CA: Stanford University Center for the study of Language and Information. Available at http://plato.stanford .edu/archives/sum2011/entries/pineal-gland/

Luke, D. P. (2008) Psychedelic substances and paranormal phenomena: A review of the research. Journal of Parapsychology, 72, 77-107. 
Luke, D. P. (2011). Discarnate entities and dimethyltryptamine (DMT). Journal for the Society for Psychical Research, 75, 26-42.

Moody, R. (1975). Life after life. New York, NY: Bantam Books.

Morse, M. L. (1997). Commentary on Jansen's paper. Journal of Near-Death Studies, 16, 59-61.

Morse, M. L., Venecia, D., \& Milstein, J. (1989). Near-death experiences: A neurophysiologic explanatory model. Journal of Near-Death Studies, 8, 45-53.

Neppe, V. M. (1983). Temporal lobe symptomology in subjective paranormal experiments. Journal of the American Society for Psychical Research, 77, 1-29.

Neppe, V. M. (1989). Near-death experiences: A new challenge in temporal lobe phenomenology? Comments on "A neurobiological model for near-death experiences". Journal of Near-Death Studies, 7, 243-248.

Noyes, R., Jr., Fenwick, P., Holden, J. M., \& Christian, R. (2009). Aftereffects of pleasurable Western adult near-death experiences. In J. M. Holden, B. Greyson, \& D. James (Eds.), The handbook of near-death experiences: Thirty years of investigation (pp. 41-62). Santa Barbara, CA: Praeger/ABC-CLIO.

Noyes, R., Jr., \& Kletti, R. (1976). Depersonalization in the face of life-threatening danger: A description. Psychiatry, 39, 19-27.

Noyes, R., Jr., \& Kletti, R. (1977). Depersonalization in response to lifethreatening danger. Comprehensive Psychiatry, 18, 375-384.

Parnia, S., Waller, D. G., Yeates, R., \& Fenwick, P. (2001). A qualitative and quantitative study of the incidence, features and aetiology of near death experiences in cardiac arrest survivors. Resuscitation, 48, 149-156.

Persinger, M. A. (1989). Modern neuroscience and near-death experiences: Expectancies and implications. Comments on "A neurobiological model for neardeath experiences." Journal of Near-Death Studies, 7, 233-239.

Persinger, M. A., \& Koren, S. A. (2005). A response to Grandqvist et al., "Sensed presence and mystical experiences are predicted by suggestibility, not by the application of complex magnetic fields." Neuroscience Letters, 380, 346-347.

Potts, M. (2011). Dulling Occam's Razor: Parsimony, elegance, and explanations of poltergeist phenomena. Paper presented at the 35th International Conference of the Society for Psychical Research, Edinburgh, Scotland. Abstract available at http://www.spr.ac.uk/main/page/conference-abstracts-2011potts

Riba, J., Valle, M., Urbano, G., Yritia, M., Morte, A., \& Barbancu, M. J. (2003). Human pharmacology of ayahuasca: Subjective and cardiovascular effects, monoamine metabolite excretion, and pharmacokinetics. Journal of Pharmacology and Experimental Therapeutics, 306, 73-83.

Ring, K. (1988). Paradise is paradise: Reflections on psychedelic drugs, mystical experience, and the near-death experience (Editorial). Journal of Near-Death Studies, 6, 138-148.

Ring, K., \& Lawrence, M. (1993). Further evidence for veridical perception during near-death experiences. Journal of Near-Death Studies, 11, 223-229.

Rodriguez, M. A. (2006). A methodology for studying various interpretations of the N,N-dimethyltryptamine-induced alternate reality. Journal of Scientific Exploration, 21, 67-84.

Rogo, D. S. (1984). Ketamine and the near-death experience. Anabiosis: The Journal for Near-Death Studies, 4, 87-96.

Rousseau, D. (2012). The implications of near-death experiences for research into the survival of consciousness. Journal of Scientific Exploration, 26, 43-80. 
Saavedra-Aguilar, J. C., \& G6mez-Jeria, J. S. (1989). A neurobiological model for near-death experiences. Journal of Near-Death Studies, 7, 205-222.

Sabom, M. (1982). Recollections of death: A medical investigation. New York, NY: Harper \& Row.

Sabom, M. (1998). Light and death: One doctor's fascinating account of near-death experiences. Grand Rapids, MI: Zondervan.

Sagan, C. (1979). Broca's brain: Reflections on the romance of science. New York, NY: Random House.

Shen, H., Jiang, X., Winter, J. C., \& Yu, A. (2010). Psychedelic 5-methoxy-N,N -dimethyltryptamine: Metabolism, pharmacokinetics, drug interactions, and pharmacological interactions. Current Drug Metabolism, 11, 659-666.

Siegel, R. K. (1980). The psychology of life after death. American Psychologist, $35,911-931$.

Siegel, R. K. (1981). Reply to Stevenson. American Psychologist 36, 1461-1462.

Smith, H. (2000). Cleansing the doors of perception: The religious significance of entheogenic plants and chemicals. New York, NY: Tarcher/Putnam.

Snyder, S. H., \& Richelson, E. (1968). Psychedelic drugs: Steric factors that predict psychotropic activity. Proceedings of the National Academy of Sciences, 60, 206-213.

Stafford, P. G., \& Bigwood, J. (1993). Psychedelics encyclopedia (3rd expanded ed.). Berkeley, CA: Ronin.

St.-Pierre, L. S., \& Persinger, M. A. (2006). Experimental facilitation of the sensed presence is predicted by the specific patterns of the applied magnetic fields, not by suggestibility: Re-analysis of 19 experiments. International Journal of Neuroscience, 116, 1079-1096.

Stevenson, I. (1981). Comments on "The Psychology of Life after Death." American Psychologist, 36, 1459-1461.

Strassman, R. (2001). DMT: The spirit molecule. Rochester, VT: Park Street Press.

Strassman, R. J. (1996). Human psychopharmacology of N,N-dimethyltryptamine. Behavioral Brain Research, 73, 121-124.

Strassman, R. J. (1997). Endogenous ketamine-like compounds and the NDE: If so, so what? Journal of Near-Death Studies, 16, 27-40.

Strassman, R. J., Qualls, C. R., Uhlenhuth, E. H., \& Kellner, R. (1994). Doseresponse study of N,N-dimethyltryptamine in humans: II. Subjective effects and preliminary results of a new rating scale. Archives of General Psychiatry, $51,98-108$.

Szara, S. (1956). Dimethyltraptamin [sic]: Its metabolism in man; the relation of its psychotic effect to the serotonin metabolism. Experientia, XII, 441-442.

Szara, S. (1969). DMT (N,N-dimethyltryptamine) and homologues: Clinical and pharmacological considerations. In D. Efron (Ed.), Psychotomimetic drugs (pp. 275-286). El Cerrito, CA: Wonderland Books.

Szara, S. (2007). DMT at 50. Neuropsychopharmacol Hungarica, 9(4), 201-205.

Tellegen, A., \& Atkinson, G. (1974). Openness to absorbing and self-altering experiences ("absorption"), a trait related to hypnotic susceptibility. Journal of Abnormal Psychology, 83, 268-277.

Twemlow, S. W., \& Gabbard, G. O. (1997). Discussion of "The ketamine model of near-death experience: A central role for the n-methyl-d-aspartate receptor" by Karl L. R. Jansen. Journal of Near-Death Studies, 16, 63-69. 
van Lommel, P. (2010). Consciousness beyond life: The science of near-death experiences. New York, NY: HarperOne.

van Lommel, P., van Wees, R., Meyers, V., \& Elfferich, I. (2001). Near-death experiences in survivors of cardiac arrest: A prospective study in the Netherlands. Lancet, 358, 2039-2045.

Wilson, S. C., \& Barber. T. X. (1983). The fantasy-prone personality: Implications for understanding imagery, hypnosis, and parapsychological phenomena. In A. A. Sheikh (Ed.), Imagery: Current theory, research and application (pp. 340390). New York, NY: Wiley.

Yensen, R. (1988). Helping at the edges of life: Perspectives of a psychedelic therapist. Journal of Near-Death Studies, 6, 149-161.

Yritia, M., Riba, J., Ortuño, J., Ramirez, A., Castillo, A., Alfaro, Y., de la Torre, R., \& Barbanoj, M. J. (2002). Determination of N,N-dimethyltryptamine and B-carboline alkaloids in human plasma following oral administration of ayahuasca. Journal of Chromatography, B, 779, 271-281.

Zaehner, R. C. (1957). Mysticism: Sacred and profane. Oxford, England: Clarendon Press.

Zingrone, N. L., \& Alvarado, C. S. (2009). Pleasurable Western adult near-death experiences: Features, circumstances, and incidence. In J. M. Holden, B. Greyson, \& D. James (Eds.), The handbook of near-death experiences: Thirty years of investigation (pp. 17-40). Santa Barbara, CA: Praeger/ABC-CLIO. 